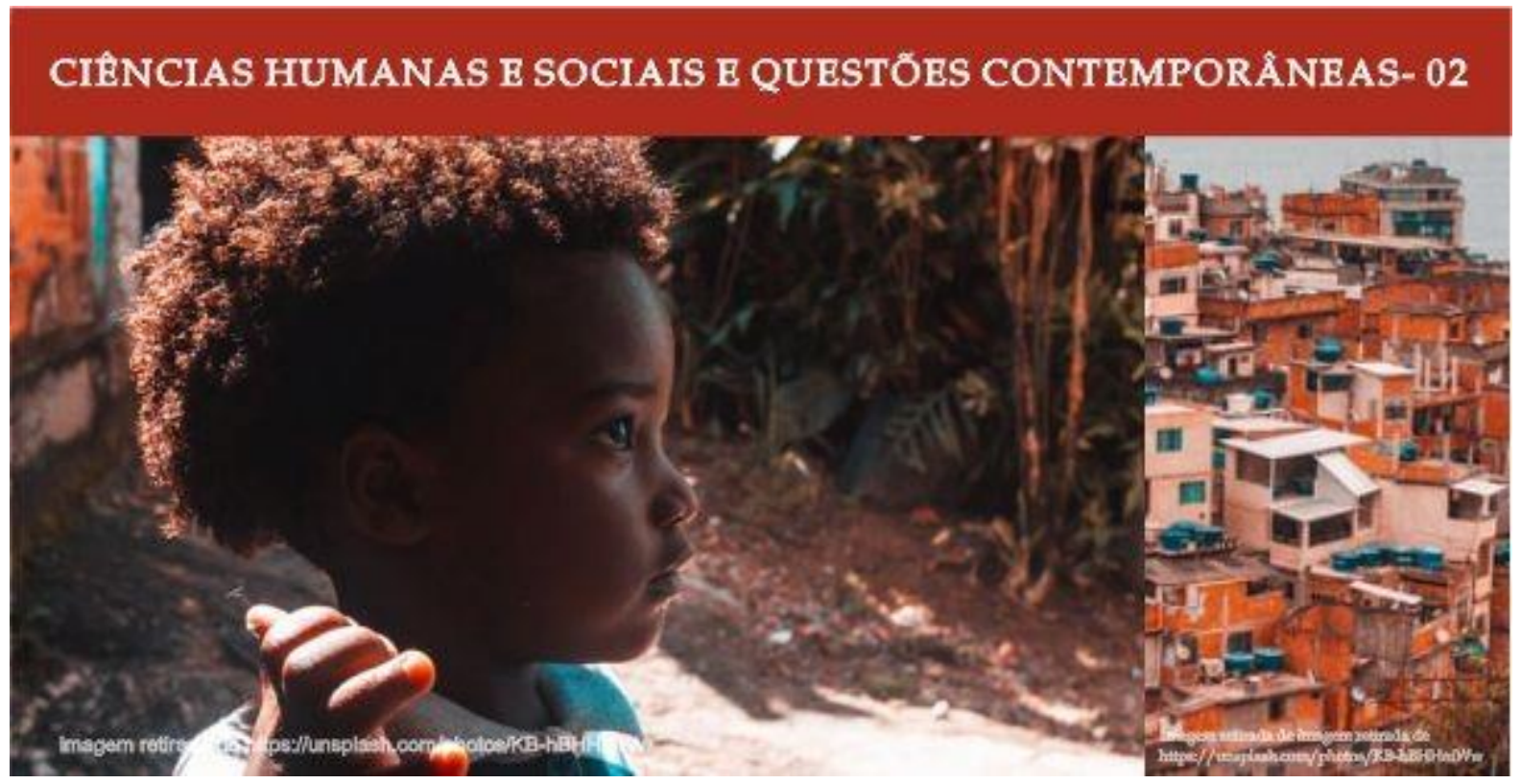

\title{
REVISTA CONTRAPONTO: UMA VISÃO HUMANIZADA DO MUNICÍPIO DO RIO DE JANEIRO E SEUS PERSONAGENS
}

\author{
Ivana Barreto \\ ORCID: https://orcid.org/0000-0002-9460-0909. \\ E-mail: ivanabarreto75@gmail.com.
}

Resumo: Os meios de comunicação de massa contribuem para o processo de reciclagem de estereótipos e preconceitos e, como resultado, muitos deles se tornam duradouros. Nesse sentido, a preocupação com a questão dos direitos humanos é inquestionável, bem como sua discussão e produção de pesquisas no âmbito universitário. Desse modo, alunos do Curso de Jornalismo da Universidade Federal Rural do Rio de Janeiro (UFRRJ) produziram uma revista para se opor ao conteúdo predominante da mídia hegemônica, apresentando visões mais humanizadas sobre o município do Rio de Janeiro e alguns de seus personagens. O objetivo foi realizar uma cobertura reflexiva, contribuindo para o questionamento dos estereótipos mencionados. A linha editorial foi baseada nos direitos humanos e na ética. Devido à falta de patrocínio e dificuldades de impressão, o produto tornou-se disponível na internet e está sendo divulgado em congressos. A metodologia incluiu pesquisas sobre os temas elencados, trabalho de campo e entrevistas. Periodicamente, foram realizadas reuniões para avaliar a produção e sua vinculação com a linha editorial. Quanto aos resultados, há o prêmio na XXIII Expocom Sudeste e a receptividade na própria universidade. Este artigo, portanto, é um relato de experiência da Revista Contraponto.

Palavras-chave: Direitos Humanos. Ética. Jornalismo. Revista. Contraponto.

\section{CONTRAPONTO MAGAZINE: A HUMANIZED VIEW OF RIO AND ITS CHARACTERS}

Abstract : The mass media contributes to the process of recycling stereotypes and prejudices and as result many of them become enduring. In this sense, the concern with the issue of Human Rights is undisputed as wellas its discussion and production of research in the university level. Thus, students from the Journalism Course of UFRRJ produced a magazine in order to oppose the prevailing contente of the hegemonic media, presenting more humanized visions about Rio de Janeiro and some of its characters. The goal was to carry out reflective coverage, contributing to the questioning of the stereotypes. The editorial line was based on the humanrights and ethics. Due to the lack of sponsorship and printing difficulties, the product became available on the internet and is being also publicized in congresses. The methodology included research on the themes listed, field work and interviews.

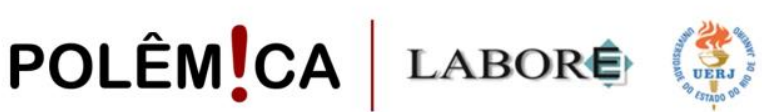

Polêmica - Revista Eletrônica da Uerj - Rua São Francisco Xavier, 524, $1^{\circ}$ andar bloco D, sl.1001 • Tels.: +55 21 2334-4088 / 4087 • http://www.e-publicacoes.uerj.br/index.php/polemica/index http://www.labore.uerj.br • laboreuerj@yahoo.com.br 
Periodically, meetings were held to evaluate the production and its link to the editorial line. As regards the results, there are the XXIII Expocom Sudeste Award and receptivity in the university it self. This article, therefore, is an experience report of the Revista Contraponto.

Keywords: Human rights. Ethics. Jornalism. Magazine. Contraponto.

\section{Introdução}

A partir do entendimento da importância do exercício da criação de um meio de comunicação alternativo no âmbito universitário, um grupo de quatro alunos da disciplina Planejamento Editorial do Curso de Jornalismo da Universidade Federal Rural do Rio de Janeiro (UFRRJ) produziu, em 2015, a revista Contraponto. Este artigo objetiva relatar a referida experiência.

Como o próprio nome sugere, a proposta da citada revista foi ser um contraponto ao conteúdo tendencioso e excludente da mídia tradicional, apresentando visões mais humanizadas sobre o Rio de Janeiro e vários de seus personagens. A sub-representação da capital fluminense na grande mídia foi o tema eleito pelos discentes para a produção da Contraponto. Desse modo, o trabalho desenvolvido pelos alunos coincide com um dos principais objetivos do Curso de Jornalismo da UFRRJ: formar profissionais e cidadãos críticos, com visão global e multidisciplinar, capazes de atuarem em um mercado especializado e competitivo. Também é preocupação de todo o corpo docente oferecer ao aluno ferramentas que viabilizem não só sua atuação intelectual como também profissional. Apesar das dificuldades relativas à infraestrutura física e à falta de equipamentos, professores e alunos comungam do desejo de realizarem um curso atento a um projeto de sociedade que objetiva a melhoria do nível de vida dos que dela fazem parte.

Este projeto, importa ressaltar, incluiu também a divulgação do veículo - por razões financeiras disponível apenas na plataforma digital - em eventos da área de Comunicação Social. O primeiro deles foi o XXXIX Congresso Brasileiro de Ciências da Comunicação, realizado na Universidade de São Paulo (USP), em setembro de 2016. Em 2018, foi a vez de levar o processo de produção de Contraponto ao IV Encontro Regional Sudeste de História da Mídia, que aconteceu na Universidade Federal Fluminense (UFF), no Rio de Janeiro. Por fim, em 2019, o projeto foi apresentado no seminário internacional Comunicação Participativa e a Luta pelos Direitos Humanos, na UERJ.

Em alguns momentos da história brasileira, a preocupação com a questão dos direitos humanos - aspecto definidor da linha editorial da revista Contraponto - se mostrou essencial.

\section{POLÊM!CA $\mid$ LABORE}

Polêmica - Revista Eletrônica da Uerj - Rua São Francisco Xavier, 524, $1^{\circ}$ andar bloco D, sl.1001 • Tels.: +55 21 2334-4088 / 4087 • http://www.e-publicacoes.uerj.br/index.php/polemica/index http://www.labore.uerj.br • laboreuerj@yahoo.com.br 
Contudo, não se deve esquecer que a mesma preocupação precisa existir em relação à forma como a mídia produz e veicula informações. A cada notícia transmitida pelo rádio, pela TV ou veiculada pelos meios impressos e digitais, percebemos que os veículos de comunicação de massa contribuem para o processo de reciclagem de estereótipos e preconceitos de toda natureza, fazendo muitos deles perdurarem. Nesse sentido, a atenção voltada para o tema ligado aos direitos humanos e suas violações é inquestionável e deve começar já no ensino fundamental. Igualmente imperativa é sua discussão e, a partir desta, a produção de pesquisas e produtos no âmbito das universidades. Importa atentar para a natureza dos desafios dos direitos humanos, especialmente do direito à comunicação múltipla - de diferentes meios de comunicação, quer sejam eles hegemônicos ou não - e aprofundada.

No que concerne aos referenciais teóricos, foram indicados ao grupo responsável pela Contraponto, num primeiro momento, autores também lidos por toda a turma da disciplina Planejamento Editorial, independente do tema escolhido para a realização de cada revista, constituindo a bibliografia básica por incluir temas relacionados ao veículo revista, à reportagem, à entrevista, apenas para citar alguns exemplos. Foram eles: Nilson Lage (2001), José Salvador Faro (1999), Cremilda Medina (1990), Marília Scalzo (2013), Sérgio Vilas Boas (1996). No que diz respeito especificamente ao grupo idealizador da revista Contraponto, foram indicados ainda os seguintes textos e autores: Constituição da República Federativa do Brasil (1988); Declaração Universal dos Direitos Humanos (DUDH); Fábio Comparato (2010) e Eduardo Bittar (2004).

A revisão de literatura costuma recorrer a publicações científicas em periódicos, livros, anais de congressos, sintetizando toda a informação existente, tanto quanto possível. Assim, foram consultados primeiramente autores que tratassem dos temas relacionados à produção de uma revista, de modo geral, e posteriormente aqueles com contribuições referentes à elaboração de um produto que inclui em sua linha editorial, como já dito, o binômio direitos humanos e ética. Partimos da premissa de que existem diferentes modos de entender a realidade, como também diversas posições metodológicas que explicitam a construção do objeto de estudo, assim como a postura e a dinâmica que perpassam a pesquisa.

Com o objetivo de melhor entender a proposta das coberturas realizadas para a revista Contraponto, partiu-se aqui da constatação de que os meios de comunicação são um importante espaço de representação na sociedade. Segundo Vaz (2013), a narrativa jornalística atribui

\section{POLÊM!CA $\mid$ LABORE}

Polêmica - Revista Eletrônica da Uerj - Rua São Francisco Xavier, 524, $1^{\circ}$ andar bloco D, sl.1001 • Tels.: +55 21 2334-4088 / 4087 • http://www.e-publicacoes.uerj.br/index.php/polemica/index http://www.labore.uerj.br・ laboreuerj@yahoo.com.br 
valores que transformam ou reforçam determinadas crenças sociais, construindo socialmente a realidade. Assim, o conjunto de ideias criadas acerca de um determinado grupo ou espaço se constitui, majoritariamente, pelos elementos simbólicos fornecidos pela mídia. A partir dessas premissas, Contraponto pretendeu realizar uma reflexão sobre a representação do Rio de Janeiro e dos cariocas no jornalismo e, mais do que isso, como esta representação influencia o imaginário sobre a cidade, objetivando uma releitura dos assuntos veiculados na mídia tradicional.

Na capital fluminense, podemos elencar atualmente quatro jornais que atingem números importantes quanto à tiragem: O Globo, Extra, Meia Hora e O Dia. Embora pertençam a empresas diferentes, todos são bem parecidos, das pautas às suas ideias e opiniões, conforme Vaz (2013). Em outros termos, compartilhando do pensamento de Rocha (2010), predomina um certo consenso sobre o que e como noticiar, evidenciando uma expressiva carência de visibilidade e diversidade na cobertura de diversos temas. As notícias são apresentadas a partir de um mesmo enfoque. Fontes e opiniões pouco divergem e/ou aprofundam a discussão.

Nesse momento, remetendo a Karam (1997), ressaltamos que o jornalismo deve apresentar visões políticas e ideológicas contraditórias, abrir espaço para o plural e o particular, "deve mostrar tanto aquilo que humaniza quanto aquilo que desumaniza o homem" (KARAM, 1997, p. 94). Desse modo, Contraponto se fundamenta em três princípios, que nortearam todo o seu processo de produção: tornar visíveis questões sociais características do Rio; empreender um jornalismo humanizado; estar na contramão da lógica mercadológica.

Todo o processo de produção da revista promoveu também o encontro com as disciplinas Fotojornalismo e Editoração Eletrônica. O grupo, formado pelos discentes Ágatha Santos, Jacqueline Suarez, Larissa Bozi e Luis Henrick Teixeira, mesmo com as dificuldades de infraestrutura que o curso enfrentou e ainda enfrenta, atingiu o objetivo lançado pela docente no início do período letivo: produção de um veículo voltado à real demanda de seu público leitor. O mesmo aconteceu com os demais grupos da disciplina Planejamento Editorial, que produziram revistas com propostas alternativas e, em certo sentido, inovadoras, quando comparadas com o que vem sendo realizado pela mídia tradicional. Saúde mental, entretenimento, cultura e o segmento feminino foram alguns dos temas dos produtos apresentados.

\section{POLÊM!CA $\mid$ LABORE}

Polêmica - Revista Eletrônica da Uerj - Rua São Francisco Xavier, 524, $1^{\circ}$ andar bloco D, sl.1001 • Tels.: +55 21 2334-4088 / 4087 • http://www.e-publicacoes.uerj.br/index.php/polemica/index http://www.labore.uerj.br • laboreuerj@yahoo.com.br 
O objetivo do projeto que culminou com a produção da revista Contraponto foi realizar, sob a orientação e supervisão da docente responsável pela disciplina - autora do presente relato -, coberturas reflexivas, aprofundadas, contribuindo para o questionamento de estereótipos e dando visibilidade aos conflitos sociais. Já no que diz respeito à linha editorial da revista, um dos primeiros aspectos definidos no seu planejamento, elegeu-se o binômio direitos humanos e ética como norteador de todo o conteúdo verbal e visual exposto nas suas páginas. No tocante ao alcance do veículo, devido à falta de patrocínio e dificuldade de imprimir um número mínimo para divulgação em associações de moradores, bibliotecas públicas, escolas e universidades, a equipe acabou optando pela disponibilização do produto na internet. Contudo, a ideia original, importa lembrar, definida no seu planejamento editorial, era divulgar a revista nas suas versões física e digital.

Contraponto reúne, em suas 72 páginas, diferentes formatos jornalísticos, como reportagem, opinião, entrevista, crônica, perfil e galeria de imagens. Uma tentativa de diversificar os assuntos e a forma como os mesmos são apresentados ao leitor. O nome da revista foi escolhido buscando estabelecer uma coerência com seu propósito de representar um olhar diferente daquele, reiteradas vezes, lançado pela mídia tradicional, hegemônica. Já na capa, a fotografia promove um diálogo com a matéria principal, apresentando ao leitor uma cena bastante comum nas favelas cariocas: uma criança soltando pipa. Segundo Rocha (2010), esses espaços são uma imagem referência do Rio de Janeiro na mídia, sendo a ênfase sempre a violência. Entretanto, a foto escolhida objetivou construir outros significados sobre os espaços mencionados. Buscou-se criar uma capa com poucos elementos, destacando desse modo a imagem.

No que diz respeito às pautas da Contraponto, versaram sobre temas relacionados à cidade e tratados pela mídia sempre de modo negativo: as favelas, os trabalhadores ambulantes e os moradores de rua. Em suas páginas, essas histórias sem dúvida ganharam espaço. Obviamente, não houve preocupação com uma narrativa objetiva e imparcial; pelo contrário, procurou-se lançar mão de um jornalismo descritivo subjetivo, capaz de mergulhar no contexto de cada personagem. Matérias voltadas para pessoas protagonistas de diferentes tipos de lutas sociais, em diversos pontos da cidade.

\section{POLÊM!CA $\mid$ LABORE}

Polêmica - Revista Eletrônica da Uerj - Rua São Francisco Xavier, 524, $1^{\circ}$ andar bloco D, sl.1001 • Tels.: +55 21 2334-4088 / 4087 • http://www.e-publicacoes.uerj.br/index.php/polemica/index http://www.labore.uerj.br • laboreuerj@yahoo.com.br 


\section{O curso de Jornalismo}

O Curso de Jornalismo da UFRRJ, criado em 2009, está entre os 34 novos cursos criados no período de 2006 a 2010, em três campi diferentes (Seropédica, Nova Iguaçu e Três Rios), tanto nas modalidades licenciatura como bacharelado, desdobramento do programa de reestruturação e expansão (Reuni) da era Lula ${ }^{1}$.

Especificamente em relação ao Curso de Jornalismo, as incursões para a sua constituição começaram ainda em 2009, quando ocorreram os primeiros concursos docentes. Seu início efetivo aconteceu, no entanto, apenas no primeiro semestre de 2010, com a entrada de 45 alunos através do Enem e do Sistema Sisu.

A proposta de criação do curso surgiu da constatação de que não havia ensino superior público em Jornalismo na Baixada Fluminense. Na região, carente e distante do Centro do Rio de Janeiro, existiam diversas universidades, faculdades e centros de ensino, porém, todos eles privados. Além disso, houve o consenso de que deveria existir a oferta de formação em Jornalismo para uma região carente de profissionais nesse setor. Afinal, as atividades da mídia em geral vêm desempenhando papel inconteste para a sociedade, uma vez considerado o poder que representam, atuando com produção, transmissão e recepção de formas simbólicas.

No tocante às disciplinas oferecidas no Projeto Pedagógico do Curso (PPC), tanto as teóricas quanto as práticas, os conteúdos e as propostas pedagógicas têm como objetivo desenvolver nos discentes um olhar crítico e humanizado para as questões sociais, além das habilidades técnicas exigidas pelo mercado, modificado de forma acentuada nas últimas duas décadas pelas Novas Tecnologias da Informação e da Comunicação (NTICs). De outro modo, podemos dizer que estamos diante de um mercado que requer, de forma crescente, um profissional multifacetado, apto a desempenhar várias funções. Com o propósito de preparar profissionais com este perfil, o curso tem como meta mesclar conhecimentos de outras áreas, como Ciência Política, Educação, Antropologia, Sociologia, História, Economia, Letras, Direito, Belas Artes, Administração e Filosofia, àqueles específicos do campo da Comunicação Social. E mais importante: sempre a partir da premissa de que o objeto do estudo do jornalismo é a informação de interesse social.

Assim, diante do multifacetado mercado de trabalho que vem se configurando nas últimas décadas, é mister repensar a habilitação do curso, incluindo, nas ementas de várias

\footnotetext{
${ }^{1}$ Período entre os anos de 2003 e 2010.

\section{POLÊM!CA $\mid$ LABORE}

Polêmica - Revista Eletrônica da Uerj - Rua São Francisco Xavier, 524, $1^{\circ}$ andar bloco D, sl.1001 • Tels.: +55 21 2334-4088 / 4087 • http://www.e-publicacoes.uerj.br/index.php/polemica/index http://www.labore.uerj.br • laboreuerj@yahoo.com.br
} 
disciplinas, tópicos voltados para um novo estudo do tratamento da notícia, singularizado, que destaca a necessidade das coberturas locais, direcionadas para a comunidade que os jornais, revistas e produtos de outras mídias não atingem. Aqui, concordamos com Jawsnicker (2008), quando afirma que os jornais deveriam refletir sobre a importância de diferenciar e singularizar a produção e o tratamento da notícia.

Afinal, partimos do pressuposto de que o leitor, o ouvinte e o expectador devem e merecem se deparar com relatos que tragam mais do que simples declarações. Narrativas que devem ir além do jornalismo oficial e declaratório. Nesse sentido, diversas disciplinas práticas, reunidas no Projeto Pedagógico Curricular (PPC) do Curso de Jornalismo, passaram a incluir, em suas ementas, conteúdos capazes de possibilitar aos futuros jornalistas o entendimento - da melhor maneira possível - das demandas e desejos dos diferentes públicos.

\section{Método}

Desde a delimitação da pauta até sua redação final, a reportagem dialogou com conceitos adquiridos em disciplinas como Introdução à Linguagem Jornalística e Planejamento Editorial. Inicialmente, o repórter realizou uma ampla pesquisa, tanto do material disponível na internet como de jornais da época. Esta pesquisa foi essencial para o entendimento das narrativas elaboradas pelos grandes veículos.

A pesquisa que deu base à produção da revista se apropriou das contribuições do método dialético no processo de investigação e de análise daquilo que era coletado no trabalho de campo, nas entrevistas. Esta opção foi decorrência do fato deste método levar o pesquisador a trabalhar sempre de forma a considerar a contradição e o conflito. Afinal, nada se adequava melhor à proposta da revista Contraponto do que voltar as atenções para as contradições e os conflitos entre o que é publicado pela mídia hegemônica, tradicional e a proposta diametralmente oposta da revista. Cumpre frisar que este método se mostrou especialmente condizente na segunda etapa do trabalho, a pesquisa de campo.

Nesse momento, o grupo de alunos pôde confrontar a realidade encontrada nas ruas com aquela exposta, estampada muitas vezes em letras garrafais, na mídia tradicional. Além disso, antes de cada entrevista ser realizada, a docente e os discentes se reuniam, no que constituiu a primeira etapa do trabalho, para, a partir da comparação com o material publicado na internet, nos jornais, revistas e veiculado pela TV e pelo rádio, perceber quais questões relevantes, não

\section{POLÊM!CA $\mid$ LABORE}

Polêmica - Revista Eletrônica da Uerj - Rua São Francisco Xavier, 524, $1^{\circ}$ andar bloco D, sl.1001 • Tels.: +55 21 2334-4088 / 4087 • http://www.e-publicacoes.uerj.br/index.php/polemica/index http://www.labore.uerj.br • laboreuerj@yahoo.com.br 
levantadas até então, poderiam ser elaboradas. Foi assim principalmente nas reportagens "Para sempre mães de Anjo" (TEIXEIRA, 2015) e "Olhe nos meus olhos, sou ser humano" (SANTOS; SUAREZ, 2015).

No caso específico de "Para sempre mães de Anjo", o objetivo foi possibilitar o debate sobre a falta de segurança dentro das instituições públicas de ensino. Falta de segurança que ficou exposta, infelizmente, pela chacina ocorrida na Escola Municipal Tasso da Silveira, em 2011. Vale lembrar aqui que o citado debate acabou se constituindo pauta de luta do movimento organizado pelas mães das vítimas.

Além disso, em todo o processo de apuração os discentes ficaram frente a frente com outros questionamentos, como a relação do local da tragédia com a comunidade. Nesse sentido, foi importante ambientar o leitor no contexto em que estão inseridos os personagens, com o intuito de promover uma melhor compreensão do simbolismo da escola para as famílias atingidas e também pelas não atingidas.

A partir daí, transformou-se numa meta a ser atingida o levantamento de questões diferentes do que já havia sido publicado. O gênero textual eleito para dar conta de narrar tamanha tragédia, após o primeiro contato com Adriana Silveira, uma das mães e presidente da ONG Anjos de Realengo, foi a entrevista, que seria realizada com as famílias. Agora, aproveitamos as contribuições de Medina (1990), quando ressalta que, diferente da espetacularização, a entrevista com finalidade de traçar um perfil humano não provoca gratuitamente, apenas para acentuar o grotesco, para literalmente condenar a pessoa - que já estaria pré-condenada - ou para glamourizá-la sensacionalisticamente. Trata-se de uma entrevista aberta, capaz de mergulhar no outro, no sentido de compreender seus valores, comportamentos, histórico de vida.

A intenção da abordagem foi conhecer a história das famílias das crianças de maneira aprofundada, e aqui se destaca o papel de ouvinte do repórter. Importa lembrar que as falas das entrevistadas, por conseguinte, não foram interrompidas. No que remete à linguagem visual, as fotografias partiram do princípio de informar, no lugar de apenas registrar.

Após a construção de cada texto, o grupo de alunos esteve mais uma vez reunido com a docente para verificar se o relato, de fato, refletia a realidade observada nas ruas. Cumpre ainda frisar que partimos da compreensão de que reportagem e investigação são sinônimos. O repórter

\section{POLÊM!CA $\mid$ LABORE}

Polêmica - Revista Eletrônica da Uerj - Rua São Francisco Xavier, 524, $1^{\circ}$ andar bloco D, sl.1001 • Tels.: +55 21 2334-4088 / 4087 • http://www.e-publicacoes.uerj.br/index.php/polemica/index http://www.labore.uerj.br・ laboreuerj@yahoo.com.br 
deve viver, dentro das limitações temporais e daquelas impostas pelas circunstâncias, a realidade dos seus entrevistados.

No caso da reportagem "Olhe nos meus olhos, sou ser humano", duas alunas da equipe da Contraponto, Jacqueline Suarez e Ághata Santos, passaram boa parte da noite com moradores de rua do bairro de Santa Cruz, na Zona Oeste do Rio. O processo começou às $22 \mathrm{~h}$, acompanhando um grupo de jovens na missão de distribuir alimentos e levar atenção a essas pessoas, invisíveis para a sociedade - e para a mídia hegemônica. A experiência continuou pela madrugada e várias situações, principalmente a das crianças que estão pelas ruas do bairro, impactaram Ághata e Jacqueline.

\section{Resultados}

Quanto à análise do trabalho realizado para a disciplina Planejamento Editorial, no caso específico da Contraponto, apontou-se para o fato de que a universidade deve promover o exercício da reflexão também nas disciplinas práticas. Ainda foi possível perceber que os discentes chegaram mais perto do que deve ser a prática jornalística.

Os alunos responsáveis pela Contraponto, tanto in loco, na realização das reportagens, quanto na redação das mesmas, foram participantes ativos, aqui dialogando com Traquina (2005). Segundo o autor, os jornalistas "são participantes ativos na definição e na construção das notícias, e, por consequência, na construção da realidade" (TRAQUINA, 2005, p. 26).

Quanto ao seu valor social, Contraponto representou uma publicação com uma clara proposta de inclusão de temas excluídos da mídia hegemônica, ou tratados de forma sensacionalista e superficial. Vale ressaltar que o veículo conquistou os prêmios de melhor revista e melhor reportagem - intitulada "Para sempre mães de Anjos", de Luis Henrick Teixeira - no XXIII Prêmio Expocom Sudeste 2016. Além disso, promoveu, em especial entre discentes do Curso de Jornalismo, o debate sobre temas normalmente excluídos da pauta dos veículos hegemônicos de comunicação.

\section{Conclusão}

É fato que no Rio de Janeiro existem grupos e espaços marginalizados em relação ao protagonismo jornalístico. São muitas as comunidades dilaceradas pela carga simbólica produzida e/ou reforçada pela mídia hegemônica, a partir de representações estereotipadas e

\section{POLÊM!CA $\mid$ LABORE}

Polêmica - Revista Eletrônica da Uerj - Rua São Francisco Xavier, 524, $1^{\circ}$ andar bloco D, sl.1001 • Tels.: +55 21 2334-4088 / 4087 • http://www.e-publicacoes.uerj.br/index.php/polemica/index http://www.labore.uerj.br • laboreuerj@yahoo.com.br 
reducionistas. Frequentemente, as narrativas são construídas com o propósito de realçar os fatos e esquecer os nomes. E a ênfase é dada a determinados temas, condenando-os a serem vistos a partir de um mesmo enfoque, segundo Rocha (2010).

Não por outro motivo, a meta perseguida pela equipe que elaborou Contraponto foi oferecer ao leitor uma visão amplificada das realidades que coexistem na cidade. Por isso, houve a valorização da diversidade social e cultural nela presentes. E, também, a apresentação ao leitor do Rio de Janeiro daquilo que ele tem de específico, fugindo dos estereótipos que o limitam a um ponto turístico ou a uma zona de violência.

A equipe que produziu Contraponto procurou se aproximar, o máximo possível, do jornalismo crítico e humanizado durante o processo de produção das matérias - buscando uma representação mais humana e próxima da realidade dos personagens. Foram esmiuçados temas de relevância social, permitindo o questionamento de valores e comportamentos. A intenção que perpassou todo o citado processo foi criar uma representação mais complexa e real, com narrativas mais sensíveis.

Ainda no início do período letivo, quando a equipe responsável pela elaboração da revista Contraponto procurou a docente para o primeiro encontro, a proposta do veículo pareceu ousada, de difícil execução. Afinal, se para jornalistas com experiência em apuração saber como abordar personagens marginalizados pela sociedade representa uma tarefa árdua, mais difícil deveria ser para estudantes do quarto período de um curso de Jornalismo.

A escolha do modo mais adequado de relatar o apurado nas ruas, nas entrevistas, foi outro aspecto que preocupou o grupo de alunos. Sem deixar de mencionar a dificuldade que acompanhou todo o processo de produção: a falta do programa específico para realizar a editoração eletrônica da revista, devido a questões burocráticas das universidades públicas. Além do mais, o curso era recém-criado e ainda estava em processo de estruturação. Contudo, depois dos dois primeiros meses, boas notícias: a equipe produzindo a todo vapor, nas ruas, com olhares humanizados, se misturando com os personagens que retratava. E o resultado indiscutivelmente surpreendeu, apontando para um jornalismo de qualidade, da pauta à impressão. Um jornalismo distante daquele que vem sendo feito pela grande mídia, constantemente incapaz de lançar um olhar humanizado sobre a cidade e seus personagens.

Cumpre lembrar que a revista Contraponto foi produzida por duas alunas do Rio de Janeiro, uma da Bahia e um aluno de São Paulo. Essa variedade cultural foi determinante para

\section{POLÊM!CA $\mid$ LABORE}

Polêmica - Revista Eletrônica da Uerj - Rua São Francisco Xavier, 524, $1^{\circ}$ andar bloco D, sl.1001 • Tels.: +55 21 2334-4088 / 4087 • http://www.e-publicacoes.uerj.br/index.php/polemica/index http://www.labore.uerj.br・ laboreuerj@yahoo.com.br 
escolha do tema e da linha editorial do veículo. Isso porque havia uma diferença considerável de percepção com relação à cidade entre as alunas cariocas e os integrantes de fora do estado. Há quase dois anos no Rio, estes já percebiam contradições entre a realidade mediada que conheciam e a que vivenciavam diariamente. Por fim, surgiu no grupo a vontade de produzir um veículo mais próximo da realidade carioca, diversificado e pautado nos conflitos sociais.

Além disso, o aniversário da cidade - que em 2015 comemorou 450 anos e vivenciava um momento de visibilidade nacional e internacional, devido aos grandes eventos nela sediados - foi mais um fator que instigou a equipe. Provocou os alunos no sentido de produzirem um material que representasse o oposto das coberturas que tão somente exaltavam as belezas do Rio de Janeiro, a partir dos pontos mais nobres da Zona Sul. Era preciso, também, voltar as atenções para os problemas públicos, mas de modo diferente das reportagens polarizadas que se multiplicavam na imprensa. Reportagens que reduziam a cidade ao paraíso ou a um problema.

Importa ressaltar que além da Contraponto outros trabalhos foram realizados para a disciplina, abrangendo o aspecto ligado à ética e aos direitos humanos. Todos eles, de modo geral, traduziram a convicção de alunos e professores de que ainda há muito a ser produzido, principalmente pelo fato do curso de Jornalismo da UFRRJ poder oferecer hoje uma melhor infraestrutura ao seu corpo docente e aos discentes.

Durante toda a trajetória percorrida pela equipe da Contraponto, quando muitas vezes os discentes perceberam que o planejamento nem sempre poderia ser totalmente cumprido e algumas decisões precisavam ser tomadas de imediato, o curso pôde oferecer ao grupo a oportunidade de aprender jornalismo da melhor maneira possível: na prática, indo a campo, apurando, por vezes apanhando, mas sempre aprendendo.

A produção da revista Contraponto viabilizou para os discentes uma das metas que constam no PPC do Curso: a vivência da prática do jornalismo. Além disso, trabalhar com um tema que é nevrálgico para a nossa sociedade, como é o dos direitos humanos, a partir de coberturas reflexivas, aprofundadas, representa uma oportunidade de questionar estereótipos, dando visibilidade aos conflitos sociais.

\section{POLÊM!CA $\mid$ LABORE}

Polêmica - Revista Eletrônica da Uerj - Rua São Francisco Xavier, 524, $1^{\circ}$ andar bloco D, sl.1001 • Tels.: +55 21 2334-4088 / 4087 • http://www.e-publicacoes.uerj.br/index.php/polemica/index http://www.labore.uerj.br • laboreuerj@yahoo.com.br 


\section{Referências}

BARTHES, R. A mensagem fotográfica. O óbvio e o obtuso. Rio de Janeiro: Nova Fronteira, 1990.

BITTAR, E. Ética, Educação, Cidadania e Direitos Humanos. São Paulo: Manole, 2004.

BRASIL. Constituição (1988). Constituição da República Federativa do Brasil. Brasília, DF: Presidência da República, 2016. Disponível em: http://www.planalto.gov.br/ccivil_03/Constituicao/ Constituiçao.htm. Acesso em: 28 jan. 2020.

BUCCI, E. Sobre ética e imprensa. São Paulo: Companhia das Letras, 2000.

COMPARATO, F. A afirmação histórica dos Direitos Humanos. São Paulo: Saraiva, 2010.

CORNU, D. Jornalismo e verdade. Lisboa: Instituto Piaget, 1999.

FARO, J. S. Realidade, 1966-1968: tempo da reportagem na imprensa brasileira. São Paulo: Editora Ulbra / AGE Editora, 1999.

JAWSNICKER, C. O futuro dos jornais: reflexões a partir da reconfiguração da esfera pública na contemporaneidade. Revista Comunicologia, Brasília, ano 2, n. 3, 2008.

KARAM, F. Jornalismo, Ética e Liberdade. São Paulo: USP, 1997.

KOTSCHO, R. A prática da reportagem. São Paulo: Ática, 2000.

LAGE, N. A reportagem. Rio de Janeiro: Ed. Record, 2001.

MATTOS, S. Desafios do jornalismo na era digital. Observatório da Imprensa, ed. 619, dez. 2010. Disponível em: http://observatoriodaimprensa.com.br/imprensa-em-questao/desafios-do-jornalismo-na-era-digital/. Acesso em: 21 jun. 2016.

MEDINA, C. Entrevista: o diálogo possível. São Paulo: Ática, 1990.

MEYER, P. The vanishing newspaper. Saving journalism in the information age. Missouri: University Press, 2004.

PENA, F. Jornalismo Literário. São Paulo: Contexto, 2006.

ROCHA, D. Da Batalha à Guerra do Rio: uma abordagem espaço-temporal da representação das favelas na imprensa carioca. In: ENCONTRO NACIONAL DE ESTUDOS POPULACIONAIS, 17., set. 2010, Caxambú. Anais. Sessão Temática 6. Caxambú: ABEP, 2010.

SANTOS, A.; SUAREZ, J. Olhe nos meus olhos, sou ser humano. Revista Contraponto, Rio de Janeiro, p. 23 $25,2015$.

SANTOS, M. R. O Futuro do jornal - Vida de papel. Gazeta do Povo, fev. 2009. Disponível em: https://gazetadopovo.com.br/caderno-g/vida-de-papel. Acesso em: 14 jun. 2019.

SCALZO, M. Jornalismo de Revista. 4. ed. São Paulo: Contexto, 2013.

TEIXEIRA, L. H. Para sempre mães de anjo. Revista Contraponto, Rio de Janeiro, p. 26-35, 2015.

TRAQUINA, N. Teorias do jornalismo: porque as notícias são como são. 2. ed. Florianópolis: Insular, 2005.

\section{POLÊM!CA $\mid$ LABORE}

Polêmica - Revista Eletrônica da Uerj - Rua São Francisco Xavier, 524, $1^{\circ}$ andar bloco D, sl.1001 • Tels.: +55 21 2334-4088 / 4087 • http://www.e-publicacoes.uerj.br/index.php/polemica/index http://www.labore.uerj.br • laboreuerj@yahoo.com.br 
UNITED NATIONS. The Universal Declaration of Human Rights. Paris, 1948. Disponível em: http://www.un.org/en/documents/udhr/. Acesso em: 10 mar. 2019.

VAZ, A. L. Jornalismo na correnteza. Rio de Janeiro: Ed. Senac Nacional, 2013.

VILAS BOAS, S. O estilo magazine: o texto em revista. São Paulo: Summus, 1996.

Recebido em: 04/03/2020.

Aceito em: 30/08/2021.

\section{POLÊM!CA $\mid$ LABORE}

Polêmica - Revista Eletrônica da Uerj - Rua São Francisco Xavier, 524, $1^{\circ}$ andar bloco D, sl.1001 • Tels.: +55 21 2334-4088 / 4087 • http://www.e-publicacoes.uerj.br/index.php/polemica/index http://www.labore.uerj.br・ laboreuerj@yahoo.com.br 